\title{
Apresentando a profissão do enfermeiro aos alunos do ensino médio - relato de experiência
} Introduction of high school students to the profession of nurse - Experience report

\section{Introdução}

$\mathrm{Na}$ qualidade de enfermeiras e docentes da Faculdade de Enfermagem da Universidade do Estado do Rio de Janeiro (ENF/UERJ), há dez anos divulgamos a enfermagem e seus profissionais com o projeto de extensão "Afinal o que é ser um enfermeiro? Falando de nós para vocês". Esta atividade foi realizada no período de março de 2000 a dezembro de 2009, com alunos do Ensino Médio de colégios da rede pública e privada do município do Rio de Janeiro. Participamos, também, do acolhimento dos alunos que ingressavam na ENF/ UERJ, esclarecendo dúvidas sobre a atuação do enfermeiro nos diferentes níveis de saúde no mercado de trabalho.

Enfermagem pode ser definida como uma "ciência humana, de pessoas e experiências com campo de conhecimento, fundamentações e práticas do cuidar dos seres humanos que abrangem do estado de saúde aos estados de doença". ${ }^{1}$ Em suas ações, a enfermagem presta assistência ao indivíduo, família ou comunidade para promover, manter ou recuperar a saúde. ${ }^{2}$

Embora a enfermagem seja praticada por profissionais de nível médio (auxiliares e técnicos) e superior (enfermeiro) que se distinguem em sua prática cotidiana de acordo com a formação profissional traduzida na complexidade de suas ações, podemos perceber, ainda nos dias atuais, que a população de uma maneira geral desconhece as atividades realizadas pelo enfermeiro. Neste grupo, muitas vezes, se encontram os jovens que ingressam na graduação em enfermagem, considerando que muitos desconhecem a profissão.

Em 1999, tivemos oportunidade de ratificar nossas observações empíricas pela realização de uma investigação com alunos da ENF/UERJ, cons-
Thelma Spindola ${ }^{1}$, Elizabeth Rose da Costa Martins', Ana Paula da Rocha Gomes ${ }^{3}$

\section{Resumo}

Trata-se do relato de experiência das ações do projeto de extensão "Afinal o que é ser um enfermeiro - falando de nós para vocês" da Faculdade de Enfermagem da Universidade do Estado do Rio de Janeiro, junto aos alunos do ensino médio de escolas do município do Rio de Janeiro. A ação tinha o objetivo de esclarecer os jovens em relação à enfermagem, às áreas de atuação do enfermeiro e ao mercado de trabalho. A metodologia adotada para o desenvolvimento da atividade consistia na realização de dinâmicas de grupo e exposição oral, estimulando o diálogo e a troca de saberes entre os profissionais e os estudantes. Os resultados indicam que os estudantes tinham pouca informação em relação às profissões da área de saúde e desconheciam a profissão do enfermeiro e o campo de atuação desse profissional. Podemos concluir que, embora na atualidade os estudantes tenham acesso às informações através de diversos meios de comunicação, ações que possibilitem o contato direto com os profissionais de saúde podem contribuir para o esclarecimento dos adolescentes em formação e tornam-se relevantes considerando o momento da escolha profissional dos jovens.

Palavras-chaves: Escolha da profissão; Adolescente; Educação em enfermagem; Educação Superior

Área Temática: Saúde

Linha da Extensão: Saúde humana e educação profissional 
tatando que estes detêm pouca informação ou desconhecem a profissão do enfermeiro quando ingressam na faculdade. ${ }^{3}$ Nos encontros com os jovens graduandos podíamos perceber que, embora na atualidade a internet seja um excelente aliado para a divulgação de informação, eles ainda ingressavam na enfermagem desconhecendo ou sabendo muito pouco sobre a profissão. Os poucos alunos que não se enquadravam nesse perfil tinham acesso à informação por atuar na área da saúde em outras profissões ou pela presença de familiares e/ou amigos como profissionais de saúde.

Foi a partir desta problemática, que surgiu o interesse de uma das autoras em esclarecer os alunos do Ensino Médio, através da realização de um projeto de extensão, para que tivessem acesso à informação e pudessem escolher uma carreira de maneira consciente, considerando que a enfermagem é uma profissão pouco divulgada e que muitos adolescentes ainda estão indecisos quanto à sua opção profissional.

Neste sentido, consideramos relevante uma maior divulgação da profissão, desmistificando a imagem que a sociedade tem acerca do enfermeiro influenciada, muitas vezes, pela forma como a mídia expõe o trabalho da enfermagem. Assim, embora as ações da enfermagem tenham importância vital nas instituições de saúde, ela é uma profissão pouco valorizada pela sociedade em decorrência de diversos fatores como o predomínio da força de trabalho feminino, a estratificação da classe em categorias, a fragmentação do poder e a baixa remuneração. ${ }^{4}$

Analisando a visibilidade do enfermeiro na visão dos profissionais de comunicação, constatou-se que, embora reconheçam a enfermagem como peça fundamental no processo de cuidado à saúde, estes profissionais "clamam por mais informação, mais visibilidade e mais voz quanto ao papel da enfermagem no cuidado à saúde". 5

Os alunos que cursam enfermagem são, em sua maioria, do sexo feminino; muitos já tentaram vestibular para outras áreas da saúde, principalmente medicina e têm afinidade com a área biomédica. ${ }^{6}$ A escolha profissional do adolescente sofre influência das representações que possui a respeito das diferentes profissões ao longo de sua vida, pelas experiências pessoais, pelas questões sociais e econômicas ou por imagens transmitidas pelos meios de comunicação que se refletem na imagem que ele faz de cada carreira. ${ }^{5}$ Neste sentido, as ações do projeto tiveram o propósito de divulgar a enfermagem, desmistificar a figura do enfermeiro associada, muitas vezes, ao estereótipo, esclarecendo o seu fazer e suas competências, procurando despertar nos alunos do ensino médio o interesse pela profissão.

\section{Metodologia}

No desenvolvimento das ações, procedemos ao planejamento das atividades realizadas ao longo do ano letivo e ficamos atentos ao calendário escolar. Na ENF/UERJ as ações ocorriam sempre no início do semestre letivo, na subárea de pesquisa em enfermagem, sendo o primeiro contato do jovem com a profissão. Com os alunos do Ensino Médio, fazíamos contato com os coordenadores pedagógicos dos colégios próximos à ENF/UERJ, em Vila Isabel, sendo incluídos bairros adjacentes localizados no município do Rio de Janeiro.

Era feito um contato inicial por telefone programando um encontro com os coordenadores de ensino das instituições para esclarecermos os objetivos do projeto, o tipo de atividade que era realizada e o tempo necessário para o desenvolvimento do projeto, sendo agendados os encontros com os alunos. Em algumas situações, visitamos previamente as turmas ou elaboramos cartazes divulgando a atividade convidando-os a participar do encontro. Retornávamos às instituições de ensino quantas vezes fossem necessárias para atendermos à demanda dos jovens interessados na temática.

Nos encontros, com duração média de 50 a 90 minutos, buscamos levantar o conhecimento dos jovens em relação à enfermagem e possíveis dúvidas que os alunos apresentassem. Procurávamos despertar o interesse dos jovens com dinâmicas de grupo e estratégias que os levassem a refletir acerca da temática e manifestar sua opinião a respeito. Recursos audiovisuais como: slides, fotografias, retro-transparências, filmes e multimídia foram adotados em todas as instituições. Esclarecíamos sobre a formação do enfermeiro, as categorias profissionais da enfermagem e sua competência, o mercado de trabalho, as Instituições de Ensino Superior que oferecem o curso, a relação candidato/vaga, e outras questões relacionadas. A síntese das informações era fornecida no 
formato de um folder para os jovens interessados e, também, através da internet na página da ENF/ UERJ e na Comunidade do Orkut, "Afinal, o que é ser enfermeiro". O telefone institucional era disponibilizado para o agendamento de uma visita à Faculdade de Enfermagem, com recepção da coordenação do projeto, para apresentação da área física da Faculdade.

Na Faculdade de Enfermagem, procurávamos focar nas áreas de atuação do Enfermeiro, no mercado de trabalho e nas distintas oportunidades e possibilidades existentes após a conclusão do curso. Oferecíamos um folder explicativo e disponibilizávamos contatos para maiores esclarecimentos. Para o desenvolvimento dessas ações contávamos com a participação de alunos bolsistas de extensão e/ou com a presença de alunos voluntários que nos auxiliavam no contato com as escolas, na elaboração do material didático e na apresentação do projeto nas instituições de ensino.

\section{Resultados}

Desde o início das atividades do projeto, tivemos contato com aproximadamente 4000 alunos em palestras e feiras de saúde ou profissões. Neste período, foram realizadas atividades nas instituições de ensino elencadas a seguir: CAP-UERJ; Colégio Estadual João Alfredo; Colégio Estadual Antônio Prado Júnior; Colégio Estadual Paulo de Frontin; Colégio Estadual Amaro Cavalcante; Colégio Estadual Antonio Houaiss; Colégio Estadual Herbert Daniel de Souza; Colégio Estadual Francisco Manoel; Colégio-Curso Intelectus; Colégio Pallas; Colégio Nosso Lar; Educandário Edith dos Santos.

Nesses encontros percebíamos que, de uma maneira geral, os jovens associam a figura do enfermeiro ao profissional do cuidado cujas atividades estavam vinculadas às ordens médicas. Desconheciam que é uma profissão de nível superior e demonstravam algum conhecimento em relação às categorias de nível técnico (auxiliares e técnicos de enfermagem). ${ }^{7}$ Ficavam surpresos com as distintas áreas de atuação do enfermeiro, tendo somente a dimensão da enfermagem clínica. ${ }^{2} \mathrm{Nes}$ te sentido, autores afirmam que "os adolescentes desconhecem a atuação do enfermeiro nas áreas de promoção, resolução e prevenção, recuperação da saúde e defesa pela qualidade de vida". ${ }^{8}$
Observamos que o aluno do Ensino Médio tinha características diferenciadas conforme a instituição. O jovem da rede pública apresentava maior déficit de informação em relação às profissões e manifestava pouco interesse pelo ingresso no curso superior. $\mathrm{O}$ aluno da rede privada, embora detivesse alguma informação, demonstrava maior interesse para o ingresso na universidade. Acreditamos que o perfil socioeconômico dos jovens influencie suas escolhas e, como consequência, muitos deles, ao concluírem o Ensino Médio, se inserem no mercado de trabalho para auxiliar na renda familiar.

Por outro lado, ao contrário do que observamos no início das ações do projeto, quando as carreiras da área da saúde despertavam grande interesse nos jovens, nos últimos dois anos os adolescentes manifestavam pouco interesse por estas profissões, em decorrência da má remuneração e das condições de trabalho precárias considerando o investimento para a formação e capacitação dos profissionais.

A dificuldade de acesso às instituições de ensino e a falta de interesse dos coordenadores pedagógicos, principalmente na rede privada, foi um fator dificultador para a realização de nossas atividades, sendo necessário diversificar as estratégias para a entrada em campo. Percebemos, ao longo dos anos, que as instituições privadas de nível superior estão cada vez ganhando mais espaço nestes colégios, divulgando seus cursos, convidando para visitas às instalações e oferecendo bolsas de estudo.

\section{Considerações finais}

Desde que iniciamos as atividades do Projeto, pudemos apresentá-lo em diversas instituições da rede pública e privada no município do Rio de Janeiro. Mantivemos contato com jovens sendo um momento gratificante em que a universidade socializava o conhecimento e sua experiência nos colégios de ensino médio.

$\mathrm{O}$ projeto foi relevante no que tange à divulgação da profissão e forneceu esclarecimentos sobre a atuação do enfermeiro, o mercado de trabalho, as áreas de exercício e a remuneração do profissional. Tivemos como retorno das ações do projeto o ingresso de cinco alunos na ENF/UERJ oriundos dos colégios de Ensino Médio onde atua- 
mos. Sabemos que este quantitativo não é expressivo, entretanto, denota a repercussão das ações, considerando que nem sempre nossa profissão é conhecida pela sociedade e, até mesmo, pelos alunos que ingressam na graduação, conforme salientam alguns autores. ${ }^{3,6}$

\section{Referências}

1. LIMA, M.J. Enfermagem o que é? Cogitare Enfermagem, São Paulo, v.10, n.1, p.71-4, jan./abr. 2005.

2. ALMEIDA, M.C.P.; ROCHA, SMM. Considerações sobre a enfermagem enquanto trabalho. In: ALMEIDA, M.C.P.; ROCHA, S.M.M.; (Org). O trabalho de enfermagem. São Paulo: Cortez; . p.15-26. 1997.

3. SPINDOLA, T.;MOREIRA, A. O aluno e a enfermagem: por que esta opção profissional? Escola Anna Nery Revista de Enfermagem, Rio de Janeiro, v.3, n.3, p. 25-36, dez. 1999.

4. NÓBREGA, M.M.; LOPES NETO, D., DANTAS, H.F.; PEREZ, V.L.A.B. O ser enfermeiro num contexto transcultural. Revista Brasileira de Enfermagem, Brasília, v. 49, n.3, p. 339-408, jul./set.1996.

5. KEMMER, LF; SILVA, MJP. A visibilidade do enfermeiro segundo a percepção dos profissionais de comunicação. Revista Latino Americana de Enfermagem Ribeirão Preto, v.15, n.2, p. 191-8, mar./abr. 2007.

6. SPINDOLA, T; MARTINS, ERC; FRANCISCO, MTR. Enfermagem como opção - perfil de graduandos de duas instituições de ensino. Revista Brasileira de Enfermagem Brasília, v.61, n.2, p. 164-9, mar./abr. 2008.

7. SPINDOLA, T; SEIBERT, SL; FRANCISCO, MTR, CLÓS, AC. A visão dos alunos do ensino médio acerca do que é ser enfermeiro. Revista Enfermagem UERJ Rio de Janeiro, v.13, n.3, p. 361-66, set./ dez. 2005.

8. KEMMER, LF; SILVA, MJP. Como escolher o que não se conhece? Um estudo da imagem do enfermeiro por alunos do ensino médio. Acta Paulista de Enfermagem São Paulo, v. 20, n.2, p. 125-30, abr./jun. 2007.

\section{Abstract}

This is an experience report for the efforts within the extension project "What is to be a nurse, after all - talking about us to you" by the Nursing School at the State University of Rio de Janeiro featuring Rio de Janeiro high school students. The effort aimed to clarify the questions regarding nursing, its activity areas and the job market. The methodology adopted to develop the activity consisted of group dynamics and oral presentation, fostering dialogue and knowledge exchange between the professionals and students. The results indicated that students had not much information about the health care professions and did not know about nursing. Our conclusion is that although students have access to information through several sources nowadays, the efforts enabling the direct contact with health professionals can contribute to make teenager student's mind and be important, considering the moment of their professional choice.

Keywords: Career choice; Teenager; Nursing education; Higher Education 